\title{
Possibilities of using the Morphological Characteristics of the Slags in Archaeo-metallurgical Studies
}

\author{
Nonis, PJWN. \\ Department of Archaeology and Heritage Management, Faculty of Social Sciences and Humanities, Rajarata \\ University of Sri Lanka, Mihintale. \\ janeenanonis2@gmail.com
}

\begin{abstract}
With regards to the technical stages of the metal-working; primary smelting, secondary melting, and smithing can be identified as the main stages between reducing ore and manufacturing metal productions. In this extensive procedure, different outcomes can be recognized and among them, slags can be defined as the most abundant and wellpreserved by-product that is left from the metallurgical activities. According to the archaeological perspective, slag fragments are known as extremely valuable artefacts that help to reconstruct the ancient industrial society. It is possible to identify the reduced ore type, smelted metal, and the type of furnace through analyzing the technical parameters of these residues from a scientific perspective. The main objective of this article is to carry out a scientific discussion on the applicability of slags as an archaeometallurgical fact in interpreting ancient culture. Slags are essentially considered on their morphological characteristics.
\end{abstract}

Keywords: Slags, Archaeo-metallurgy, Smithing, Smelting, and Ore 


\section{Introduction}

The earliest evidence of metal's use in Sri Lanka was reported from the Protohistoric contexts. Which represented an advanced stage of iron-based metal technology during the Protohistoric phase (Mendis,2019,13). According to literary and archaeological evidence, the use of metals like gold, silver and the production of artificial materials such as glass increased during the early and middle historical periods. The words such as Kabara, Thambara, Thopasha, Kahapana, Massaare found in Brahmi Inscriptions which symbolize the metal-based social and economic background in contemporary Sri Lanka. (ibid,19-20). Moreover, the material evidence of metal productions, furnaces, slag fragments, and crucibles are also holding a considerable significance in archaeology and it is possible to find out more information about land use, resource manipulation as well as the trading systems of the ancient man by analyzing them.

Among the metallurgical artefacts, slag fragments are extremely valuable in archaeology as they help to reconstruct ancient industrial practices. According to Miller, slags are the durable waste by-products of a variety of metallurgical operations, predominantly primary smelting (to reduce ores to metal), secondary melting (to purify, consolidate or mix metals such as gold or copper and tin), and smithing (to work metal into finished products by hot forging) (Miller and Killick,2004, 24). Furthermore, it is known as the most common waste product of smithing which is the mixed remains of oxidized flakes of metallic iron with the fuel ash, other contamination debris such as flux, and the lining of the hearth (Dunster and Dungworth,2012,01). Furthermore, other slag-like materials with different types also can be found in metal-working areas such as cinder and clinkers. According to Morton and Wingrove slags can be defined as drossy solid materials that collect on the top of molten slag, a mass of material infusible at the working temperature of the furnace, embedded in partially fused materials (ibid). These fragments are important in interpreting the chain operation of the manufacturing process. The present article is attempting to examine the value of slags as archaeological evidence and the possibilities of using it to answer certain 
questions of the past. There are many analytical approaches that can apply to analyze the slags, and the present research especially focuses on the morphological characteristics of the slags.

\section{Materials and Methods}

The research will be based on 350 slag remains collected as a surface collection from an area of 1.6 kilometres, lies in the right bank of the spill of Giants' tank (Yodhawewa), Mannar, under the project of Lower Malwathi-Oya Basin Archaeology (LMBA), conducted by the Department of Archaeology and Heritage Management, the Rajarata University of Sri Lanka on March 2018. Fragments were primarily categorized from the morphological perspective and each fragment was considered by its length, width, height, weight, density, colour, and surface. Density (length $\mathrm{x}$ width $\mathrm{x}$ height) calculated according to the formula; $\mathrm{d}=\mathrm{m} / \mathrm{v}$ and the colour identified by the Geological Rock Colour Chart. Surface considered as regular or irregular, rough or smooth, flat or wavy, the density of lacunas, and profile features (colour, diameter of lacunas).

\section{Results and Discussion}

Generally, the high density of a slag symbolizes an ore type that is enriched with high mass elements such as Iron, Copper, Nickel, Chromium, Cobalt, Manganese, and Zinc. But it is not appropriate to decide without a proper chemical analysis since the density of slag is also associated with its placement in the furnace. In a tapped furnace, smelted metal assembled in the bottom part due to the high density and the wastage including slags remains in the upper part and gradually drains out from the taps due to the low density. Therefore, even the same ore and the same furnace were used, slags occurred with various ranges of density according to their placement level in the furnace. Morphologically, analyzing the density together with colours and surface features may reveal certain factors related to slag residues (Miller and Killick,2004,24).

The surface features of slag can be more informative and may represent the stage of the metal-working, type of the furnace, related metal, and many more. Slags 
enriched with lacunas and have a rough, wavy surface can be identified as smelting slags in the furnace that went through the process of slow cooling and high oxidizing. It may contain macroscopic crystals of Iron Silicate or Iron Oxide minerals. And if it attracts to the magnet, it may contain the Iron Oxide Magnetite (ibid,26). Dense slags with a smooth surface that resembles solidified lava can be recognized mostly in tapped furnaces. Due to the high viscosity, the molten slag assembles in the lower part of the furnace and drains out from the taps as a liquid. After the solidification, it resembles a flaw-type wavy surface, and smoothness occurred due to the fast cooling process (ibid,24) (Figure 01).

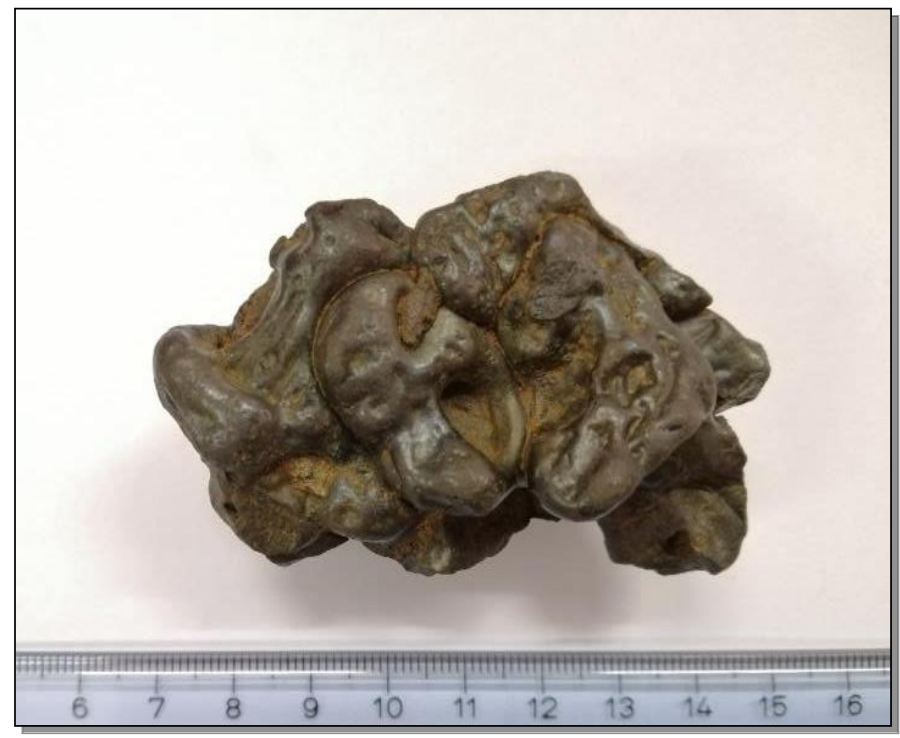

Fig.01 Smooth flaw-type wavy slag. Scale in cm, Images and data Copyrights: WMTB Wijepala

The slags that symbolize rough freaky surface with light blue-green spots can be recognized as weathered copper slags that contain Copper Carbonate Malachite. Most of them are easily broken as they try to release the small copper placements from their matrix (ibid,26). Glass and Glazed type residues are mostly defined as smithing slags since they are found clustered in areas of smithing forges. Glass-like droplets only contain Iron Oxide and glass due to fast freezing and silicate 
crystallizing (ibid). But according to Justine Bayley, glazed type residues occurred in the process of blast furnaces (Bayley,et.al,2008,14) (Figure 02).

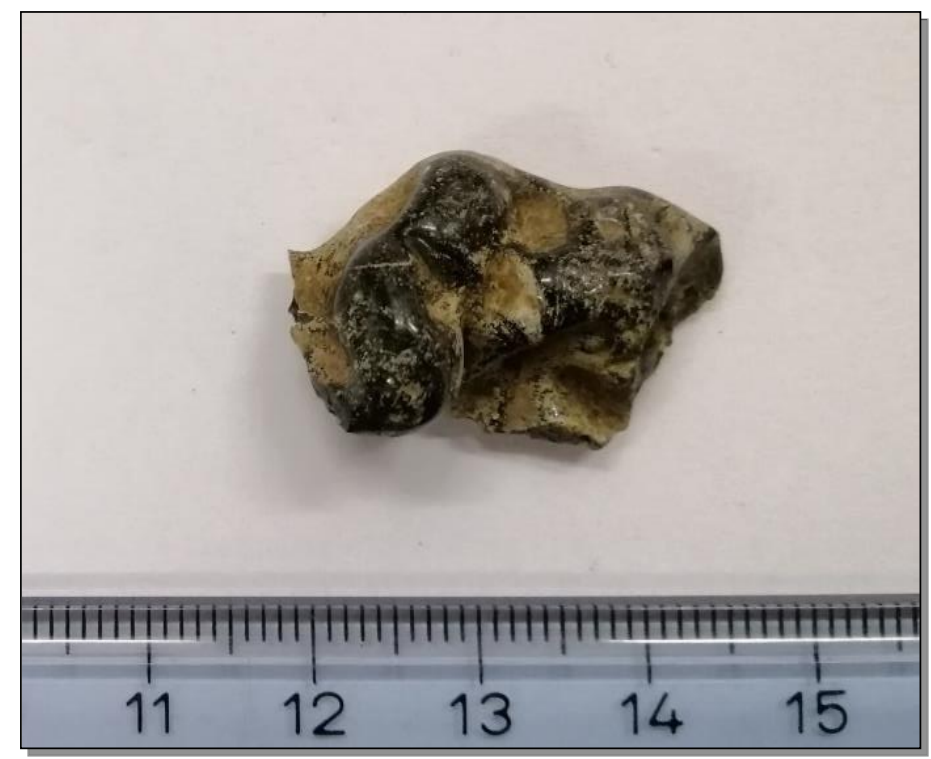

Fig.02.Glass-likeslag. Scale in cm, Images and data Copyrights:

WMTB Wijepala

Some residues are morphologically similar to Fayalite; which occurs in ultramafic igneous rocks with high containment of Iron and Magnesium. Also known as $\mathrm{Fe}_{2} \mathrm{SiO}_{4}$ - Iron crystallite; iron-rich end-member of the Olivine Solid Solution series. As Sri Lanka is not a volcanic context, it is possible to assume it is an occurrence of Iron smelting. It may contain Iron and Magnesium as well (assignmentpoint.com,2019).

The raw ores contain a vast collection of elements that represent various colours. After the reduction of ore, smelted metal and the wastage including slags received different colours due to the interactions between elements, fluxes, fuel, and gases. The oxidization is the main cause of the occurrence of many colours and the elements that did not fuse in the smelting stage also can identify as an impact that should be mentioned. According to the colour and magnetically attracted 
percentage of slags, it is possible to develop a hypothesis on the containment of Iron, Nickel, Cobalt, and their alloys since they are the main metallic elements that reacted to the magnet (Britannica,2019). Therefore, even it is not highly accurate, it is necessary to use this method as a logistic statement. Typically, Iron includes in slag fragments represents the oxide state as $\mathrm{FeO}$ and $\mathrm{Fe}_{2} \mathrm{O}_{3}$. Generally, $\mathrm{FeO}$ provides the black colour and $\mathrm{Fe}_{2} \mathrm{O}_{3}$ provides the red colour (JCEFA,2008). According to the containing percentage, slag colour deviates between red and black while the brown assembles in the centre (Figure 03).

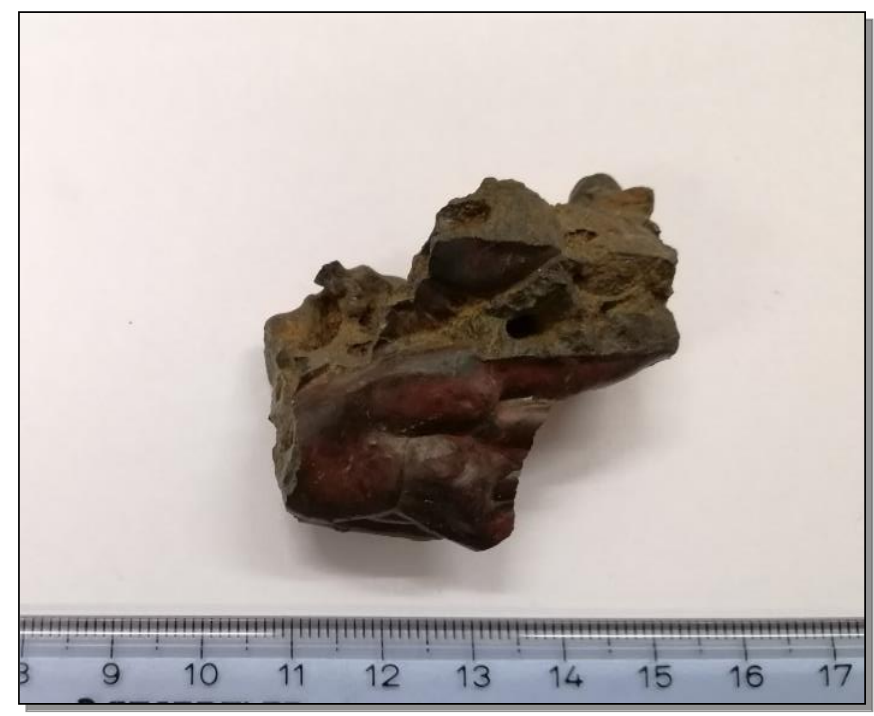

Fig.03.Red Smooth flaw-type wavy slag. Scale in cm, Images and data Copyrights: WMTB Wijepala

In the process of Iron smelting, $\mathrm{CaCO}_{3}$ is used as a flux that supports abstracting the metal from the dross and clustered the wastage to form slags (Mcdonnall,1986). $\mathrm{Ca}\left(\mathrm{AlO}_{2}\right)_{2}$ that derives from $\mathrm{CaCo}_{3}$ also can be a cause of the colour formation of slags (Figure 04). 


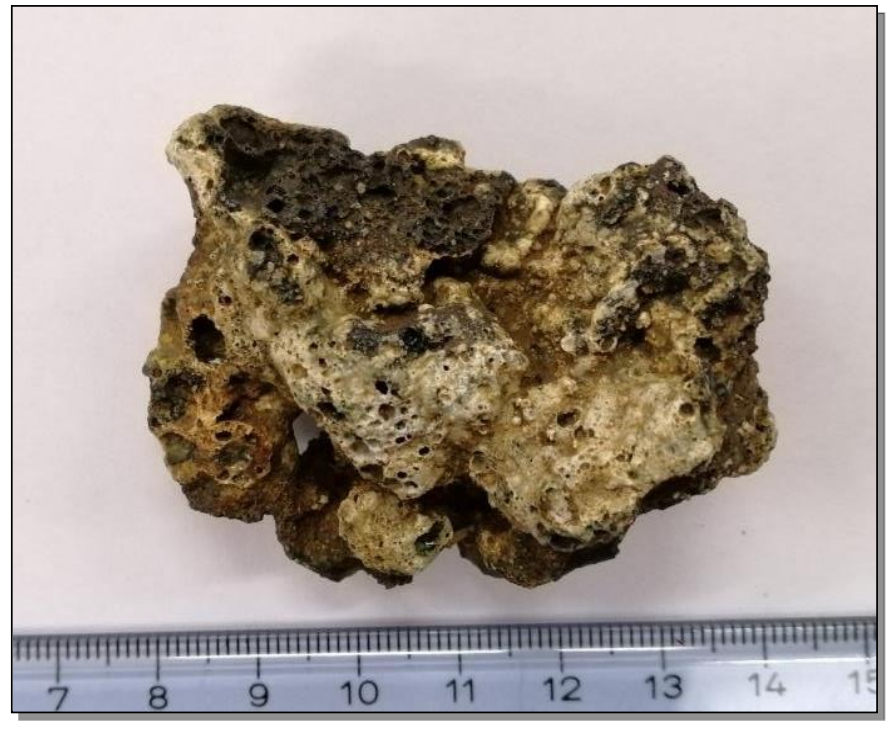

Fig.04 Slag including $\mathrm{CaCo}_{3}$. Scale in $\mathrm{cm}$, Images and data Copyrights: WMTB Wijepala

Nickel is known as an extremely associated metal with Copper and the combination creates green, grey, and blue colour (Britannica,2019). A slag may contain Nickel or Cobalt if it indicates above $80 \%$ attraction on the magnet even though it is less indicating a colour related to black or red. If there are light bluegreen spots on its surface represents the copper containment. And as copper is a non-magnetic metal, it may be nickel that alloying with copper. Also, slag can be contained cobalt as some of them symbolized cobalt blue.

In the process of smelting, not only metallurgical slags but also organic fusions known as non-metallurgical slags can be found. When the fused state of the furnace, some organic materials are partially fused and saved as slags. Vitrified thatch, vitrified dung, and vitrified hearth lining are typically recognized as biomass or non-metallurgical slags (Miller and Killick,2004,27). They are most similar to metal slags and for highly accurate data it is appropriate to follow a chemical analysis. According to the morphological factors, if it contains $15 \%$ magnetic attraction, might be a non-metallurgical fragment (Figure 05). 


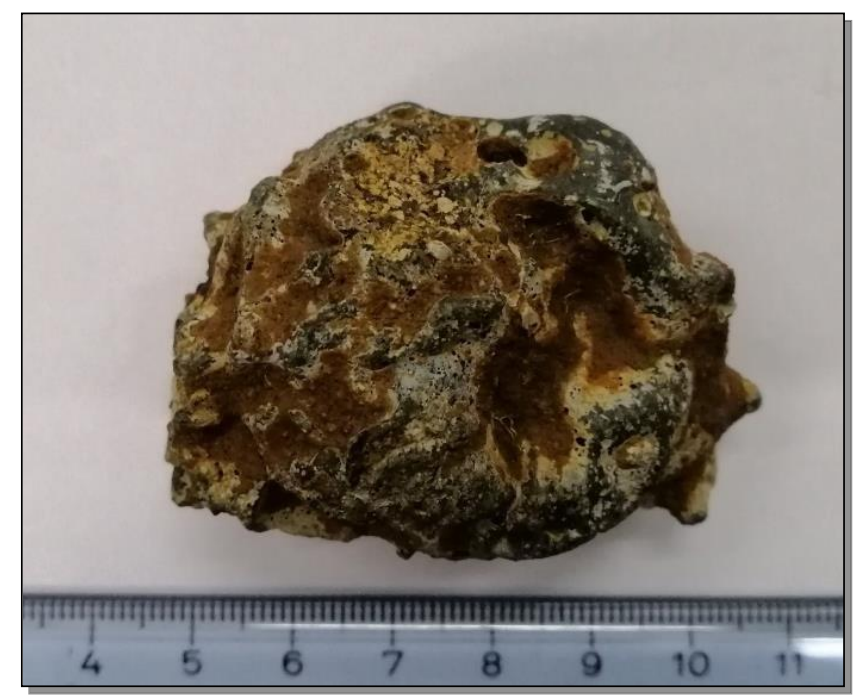

Fig.05.Non-metallurgical slags Scale in cm, Images and data Copyrights: WMTB Wijepala

\section{Conclusion}

As above mentioned, we can recognize high applicability in using the terms of characteristics and technical parameters of slag fragments, to identify the development of ancient metallurgy in a particular area. Even without chemical analyses; information related to the type of ore, smelted or smithed metal, and the technology of the furnace can be vastly analyzed through the extreme support of morphological factors. For more accurate data it is appropriate to follow a chemical analysis based on microstructure and chemical composition. Other than SEM (Scanning Electron Microscope) and ICP-OES (Inductively Coupled Plasma - Optical Emission Spectrometer), EDXRF (Energy Dispersive X-ray Fluorescence spectroscopy) also can be used for data with more accuracy. 


\section{Acknowledgements}

The materials used in the present study were obtained from the excavation of the Giants' Tank furnace site (2018) done by Mr WMTB Wijepala, Senior Lecturer of the Department of Archaeology and Heritage Management, Rajarata University of Sri Lanka. I would like to extend my gratitude towards him for granting me permission to use these materials in the present research and all the data and illustration copyrights are bound to him.

\section{References}

Bataillon, L., Bayley, J., Crossley, D., Ponting, M. (2008).Metals and Metalworking: A research framework for archaeometallurgy, The Historical Metallurgy Society Ltd, London, UK

Bullas, S.G. (1994).Identifying your local slag...the use of quantitative methods and microstructure analysis in determining the provenance of British bloomary slags from the late Iron Age to the end of the Roman occupation.

Chattopadhyay, P.K. (1984).Archaeometallurgical Studies in Indian subcontinent: A survey on metallography of iron objects, Indian Journal of History of Science.

Deraniyagala, S.U. (1992).Pre History of Sri Lanka, Department of Government Printing, Government of Sri Lanka.

Dunster, J., Dungworth, D. (2012).Blacksmiths' Fuel; The Analysis of slads from archaeological and contemporary iron-working,Research report series no. 162012, English Heritage (Acadamia.edu).

About IAMS. (2019). Institute for archaeometallurgical studies, UCL,Londens' Global university.

Juleff, G. (1996). An ancient wind-powered iron smelting technology in Sri Lanka, Nature, Vol 379. 
Juleff, G. (2009).Technology and evolution: a root and branch view of Asian iron from firstmillennium BC Sri Lanka to Japanese Steel, World Archaeology, Vol. 41, No. 4, Taylor \& Francis, Ltd.

Killik, D., Fenn, T. (2012).Archaeometallurgy: The Study of Preindustrial Mining and Metallurgy, Annual Review of Anthropology, Vol 41, pp. 559-575, Available at SSRN:https://ssrn.com/abstract=2158255 or http://dx.doi.org/10.1146/annurev-anthro$\underline{092611-145719}$

McDonnell, J.G. (1986). The classification of early ironworking slags: vol I, University of Aston in Birmingham.

Mendis, D.T. (2019).Madya deduruoya ha Mee oya nimnaye janawasa purawidyawa (Sinhala),Rajarata University of Sri Lanka, Wimal Printers, Anuradhapura.

Miller, D., Killick, D. (2004).Slag identification at southern African archaeological sites, Journal of African Archaeology, Vol 2 (1), www.researchgate.net.

Solagarachchi, R. (2011).Ancient iron smelting technology and the settlement pattern in the Kiri Oya basin in the dry zone of Sri Lanka, (Ph.D. Dissertation), University of Florida.

Somadeva, R. (2010).Archaeology of the UdaWalave basin, PGIAR Publications, Tharanjee Printers, Maharagama.

Wijepala,W.M.T.B.(2013).Parani shri lankeeya yakada nishpadnaye thakshanika paramithin (Sinhala), The Journal of Archaeology and Heritage Studies, vol I, Department of Archaeology and Heritage Management of Rajarata University of Sri Lanka. 69th JECFA, FAO JECFA, Monographs 5 (2008) 